\title{
Métodos de conservação de amostras de leite para determinação da contagem bacteriana total por citometria de fluxo
}

\author{
Laerte Dagher Cassoli ${ }^{1}$, Paulo Fernando Machado ${ }^{1}$, Arlei Coldebella ${ }^{2}$ \\ ${ }^{1}$ Clínica do Leite - Departamento de Zootecnia - ESALQ/USP - Piracicaba, SP. \\ 2 Embrapa Suínos e Aves - Concórdia, SC.
}

RESUMO - Avaliou-se o efeito da temperatura de armazenamento e da idade da amostra sobre a contagem bacteriana total de amostras de leite conservadas com azidiol para verificar a possibilidade de utilização de uma única amostra nas análises previstas na Instrução Normativa 51 (IN-51). Utilizaram-se 320 alíquotas de leite coletado de um tanque de expansão para avaliação de três temperaturas de armazenamento - a $0{ }^{\circ} \mathrm{C}$ (congelada), $7{ }^{\circ} \mathrm{C}$ (refrigerada) e $24{ }^{\circ} \mathrm{C}$ (à temperatura ambiente) -, três tipos de conservação (bronopol, azidiol e sem conservante) e quatro idades da amostra (1, 3, 5 e 7 dias). Para contagem bacteriana total, foram consideradas controle amostras refrigeradas, com azidiol e amostras de um dia e, para composição e contagem de células somáticas (CCS), os controles foram amostras refrigeradas, com bronopol e de um dia. Nas amostras conservadas com bronopol, a contagem bacteriana total foi menor que na controle, independentemente da idade e da temperatura. O mesmo foi observado nas amostras com azidiol e congeladas. Amostras com azidiol apresentaram aumento da contagem bacteriana total, independentemente da idade, enquanto, naquelas que não receberam azidiol, a contagem bacteriana total foi superior à das amostras refrigeradas, conservadas com azidiol e de um dia. As amostras conservadas com azidiol e refrigeradas tiveram aumento linear na contagem bacteriana total de 0,0058 log por dia, o que pode ser considerado sem importância prática. Amostras conservadas com azidiol e refrigeradas apresentaram CCS menor, em todas as idades, em relação a amostras refrigeradas e conservadas com bronopol. Os teores de gordura e lactose reduziram após o quinto dia. Foi necessária a coleta de duas amostras: uma destinada à determinação de CCS e da composição contendo bronopol e outra para contagem bacteriana total contendo azidiol. Amostras para contagem bacteriana total podem ser analisadas em até sete dias, se mantidas a $7^{\circ} \mathrm{C}$ e adicionadas de azidiol.

Palavras-chave: azidiol, bronopol, contagem bacteriana total, contagem de células somáticas, temperatura, tempo

\section{Milk sample conservation methods to determine the total bacteria count by flow cytometry}

\begin{abstract}
The objective of this study was to evaluate the effect of storage temperature and sample age on the total bacterial count (TBC) of milk samples preserved with azidiol to verify whether a single sample could be used to perform regulatory milk analysis under the Normative Instruction 51 (IN-51). Three hundred and twenty milk aliquots were used collected from an expansion tank to assess three storage temperatures $\left(0^{\circ} \mathrm{C}\right.$ - frozen: $7{ }^{\circ} \mathrm{C}$ - refrigerated, and $24{ }^{\circ} \mathrm{C}-$ room temperature), three types of conservation (bronopol, azidiol and no preservative) and four sample ages (1, 3, 5, and 7 days). For the total bacteria count, refrigerated control samples, with azidiol and one day old samples, and for composition and somatic cell count (SCC), the controls were defined as one day old refrigerated samples containing bronopol. Samples conserved with bronopol presented lower total bacteria count than the control regardless of storage temperature and sample age. Milk samples conserved with azidiol and stored refrigerated presented lower SCC, regardless of age, compared to refrigerated samples conserved with bronopol. The fat and lactose contents decreased after the fifth day. Two samples had to be collected: one for SCC determination and composition containing bronopol and another for the total bacteria count containing azidiol. Milk samples used for total bacteria count can be tested up to 7 days if they are kept at $7{ }^{\circ} \mathrm{C}$ with the addition of azidiol.
\end{abstract}

Key Words: azidiol, bronopol, somatic cell count, temperature, time, total bacteria count

\section{Introdução}

A aprovação da IN-51 pelo MAPA foi um marco para o setor leiteiro. Essa lei determina novas variáveis de avaliação da qualidade do leite cru, preconizando que todo leite produzido no País e processado em estabelecimentos sob fiscalização federal deve ser mensalmente submetido a análises de contagem bacteriana total, CCS e composição por um dos laboratórios credenciados pelo MAPA(BRASIL, 2002). 
No Brasil, em razão do grande número de fazendas e da extensão territorial, torna-se necessária a utilização de conservantes nas amostras utilizadas para as análises, ao contrário do que ocorre em alguns países que utilizam a refrigeração como mecanismo de preservação (Estados Unidos, 2001). Nesses casos, a curta distância entre as fazendas e os laboratórios possibilita a análise em no máximo 48 horas após a coleta, como recomendado pela International Dairy Federation (International Dairy Federation, 1995).

O conservante bronopol é amplamente utilizado na conservação de amostras destinadas à análise de composição e contagem de células somáticas. Além do conservante, a refrigeração e análise em no máximo três dias após a coleta das amostras são fatores importantes para manutenção da integridade da amostra e obtenção de resultados confiáveis (Bertrand, 1996; Meyer, 2003; Monardes et al., 1996; Van de Voort et al., 1987).

Para análise de contagem bacteriana total, o conservante mais recomendado atualmente é o azidiol, e amostras conservadas com este composto podem ser analisadas até quatro dias após a coleta, se mantidas sob refrigeração a $4^{\circ} \mathrm{C}$ (Barcina et al., 1987; Elizondo et al., 2007; Gonzalo et al., 2003; Ninane et al., 2000; Seskena \& Jankevica, 2007).

Este estudo foi realizado com os objetivos de verificar a possibilidade de utilizar uma única amostra, conservada com azidiol, para realização das análises previstas na IN-51, visando reduzir custos com material de coleta e de transporte, e analisar os efeitos da temperatura de armazenamento e da idade da amostra sobre a contagem bacteriana total.

\section{Material e Métodos}

O leite utilizado foi coletado do tanque de expansão do rebanho leiteiro do Departamento de Zootecnia da Escola Superior de Agricultura “Luiz de Queiroz”(ESALQ/USP) e homogeneizado acionando o agitador do tanque durante cinco minutos. Depois, foi transferido com auxílio de uma concha para um galão limpo e seco e encaminhado ao laboratório.

O leite foi dividido em 320 frascos plásticos esterilizados, com $50 \mathrm{~mL}$ de capacidade, que foram alocados num arranjo fatorial (4 tempos de análise $\times 3$ conservantes $\times 3$ temperaturas), com dez frascos para cada tratamento.

Nas avaliações de conservação, foram testadas três situações: adição de bronopol, de azidiol e sem adição de conservante na amostra. O bronopol em forma de pastilha foi adquirido da empresa D\&F Control (Microtabs II). Cada pastilha possui $8 \mathrm{mg}$ de bronopol (2-bromo-2nitropropano-1,3-diol) e 0,3 mg do agente antifúngico natamicima. Uma pastilha foi utilizada para cada $50 \mathrm{~mL}$ de leite. A solução de azidiol foi preparada de acordo com Barcina et al. (1987), com 0,15\% de cloranfenicol e 3,6\% de azida sódica. Quatro gotas (160 uL) da solução foram utilizadas para cada $50 \mathrm{~mL}$ de leite.

Para avaliação do efeito da temperatura de armazenamento, foram utilizadas as seguintes condições: congelamento a $0{ }^{\circ} \mathrm{C}$, resfriamento a $7{ }^{\circ} \mathrm{C}$ e temperatura ambiente a $24^{\circ} \mathrm{C}$. Nas amostras sem conservante, foram testadas apenas duas temperaturas de armazenamento, uma vez que amostras sem conservantes e a temperatura ambiente degradam rapidamente, em decorrência do rápido crescimento bacteriano.

O efeito da idade da amostra sobre os resultados da contagem bacteriana total foi avaliado um, três, cinco e sete dias entre a coleta e a análise das amostras. Para avaliação dos teores de gordura, proteína, lactose e sólidos totais e contagem de células somáticas, amostras conservadas com bronopol, armazenadas a $7^{\circ} \mathrm{C}$ e analisadas um dia após a coleta foram consideradas controle. No caso da contagem bacteriana total, foram consideradas controles amostras conservadas com azidiol, armazenadas a $7^{\circ} \mathrm{C}$ e analisadas um dia após a coleta, como considerado em outros trabalhos (Barcina et al., 1987; Gonzalo et al., 2003; Ninane et al., 2000).

As amostras foram analisadas nos equipamentos Bactocount (Bentley Instruments, 2004), Bentley 2000 (Bentley Instruments, 1995a) e Somacount 300 (Bentley Instruments, 1995b) para determinação da contagem bacteriana total e contagem de células somáticas, respectivamente. Os equipamentos Bactocount e Somacount utilizam a metodologia de citometria de fluxo e o Bentley 2000 emprega a metodologia de absorção infravermelha.

Os dados foram analisados usando o procedimento PROC GLM do SAS (2006) e a análise de variância foi realizada considerando os efeitos de conservante, temperatura, idade das amostras e suas interações. No desdobramento da análise estatística, foram utilizados o teste de Tukey para os efeitos de conservante e temperatura e a análise de regressão para idade das amostras.

A contagem de células somáticas (x $10^{3}$ células $/ \mathrm{mL}$ ) foi transformada em logaritmo natural (LCCS) e a contagem bacteriana total (x $10^{3} \mathrm{UFC} / \mathrm{mL}$ ) transformada em logaritmo na base 10 .

\section{Resultados e Discussão}

A maioria dos efeitos foi significativa, com exceção de gordura (conservante $\times$ idade e conservante $\times$ temperatura $\times$ idade) e contagem de células somáticas (conservante $\times$ 
idade). Como a interação tripla foi significativa para todas as variáveis, exceto para gordura, optou-se por sua análise para todas as variáveis.

$\mathrm{Na}$ análise das médias do logaritmo da contagem bacteriana total $\left(10^{3} \mathrm{ufc} / \mathrm{mL}\right)$, amostras conservadas com bronopol apresentaram contagem bacteriana total inferior à das amostras controles, independentemente da idade das amostras e da temperatura de conservação (Tabela 1).

Essa observação pode ser explicada pela ação bactericida do bronopol, que, provocando danos às células bacterianas, impossibilita que sejam identificadas pelo sistema óptico do equipamento, portanto, não é recomendável sua utilização em amostras destinadas à análise de contagem bacteriana total (Bentley Instruments, 2004). Da mesma forma, amostras conservadas com azidiol e congeladas apresentaram menor contagem bacteriana total em relação às amostras resfriadas, independentemente da idade da amostra. Sabe-se que o congelamento pode provocar injúrias nas células bacterianas, o que também impossibilita sua identificação. Portanto, as amostras provavelmente não sofreram congelamento durante o transporte até o laboratório, fato comum quando há utilização em excesso de gelo químico nas caixas térmicas empregadas no transporte. A quantidade de gelo a ser utilizada deve ser dimensionada de acordo com o tamanho da caixa térmica e a quantidade de amostras a serem acondicionadas (International Dairy Federation, 2005).

Por outro lado, amostras conservadas com azidiol e mantidas a temperatura ambiente apresentaram maior contagem bacteriana total, independentemente da idade, o que salienta a importância da refrigeração na conservação das amostras, uma vez que a utilização do conservante, por si só, não é suficiente para cessar o crescimento bacteriano.

Os resultados de contagem bacteriana total obtidos para amostras congeladas e mantidas a temperatura ambiente ressaltam a importância de se manter a temperatura de resfriamento constante durante o transporte das amostras para evitar o congelamento ou aquecimento.

Nas amostras que não receberam azidiol, a contagem bacteriana total foi superior à das amostras resfriadas com um dia de idade, mesmo quando mantidas sob refrigeração. A refrigeração pode ser utilizada como única forma de conservação de amostras, desde que a temperatura não ultrapasse $4{ }^{\circ} \mathrm{C}$ (International Dairy Federation, 1995). Portanto, é fundamental garantir que amostras resfriadas a temperaturas superiores, como avaliado neste estudo, recebam o conservante. Seria interessante que os laboratórios disponibilizassem os frascos para coleta contendo solução de azidiol na quantidade adequada. Esta solução, por sua vez, deveria conter um corante como indicador de sua presença na amostra.

Já as amostras conservadas com azidiol e resfriadas tiveram aumento linear na contagem bacteriana total ao longo do tempo (Figura 1). O aumento foi de 0,0058 log por dia, ou $2,17 \times 10^{3} \mathrm{ufc} / \mathrm{mL}$, o que pode ser considerado pequeno e sem importância prática. Os programas de pagamento por qualidade propostos pelas indústrias laticinistas estabelecem classes de pagamento com amplitude de 20 a $650 \mathrm{mil}$ ufc/mL e aumento diário

Tabela 1 - Logaritmo da contagem bacteriana total para cada conservante, temperatura e idade das amostras de leite

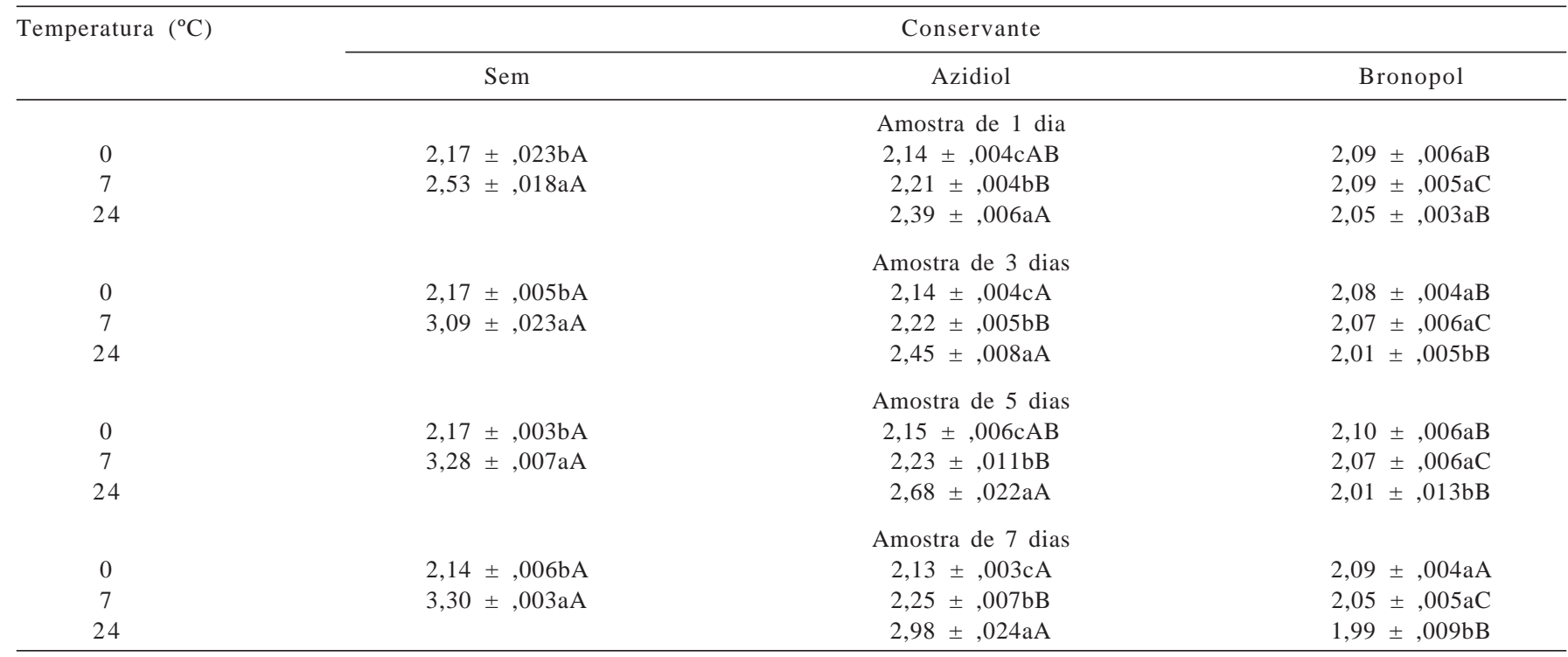

Médias seguidas de letras maiúsculas diferentes nas linhas diferem $(\mathrm{p} \leq 0,05)$ pelo teste de Tukey.

Médias seguidas de letras minúsculas diferentes nas colunas diferem $(\mathrm{p} \leq 0,05)$ pelo teste de Tukey dentro da idade. 




Figura 1 - Contagem bacteriana total em amostras de leite conservadas com azidiol ou bronopol e analisadas em quatro idades.

observado não ocasionaria mudança na classe de pagamento, portanto, não prejudicaria os produtores.

Há citações na literatura preconizando que amostras com azidiol e refrigeradas podem ser analisadas até quatro dias após a coleta (Barcina et al., 1987; Gonzalo et al., 2003; Ninane et al., 2000; Seskena \& Jankevica, 2007). Neste estudo, porém, observou-se que um período maior, de até sete dias, entre coleta e análise pode ser empregado, pois não comprometeria os resultados.

Dessa forma, para amostras destinadas à análise de contagem bacteriana total,sugere-se a utilização do conservante azidiol em associação à refrigeração. No entanto, essa mesma amostra não pode ser utilizada para a análise de
CCS. Amostras conservadas com azidiol e resfriadas tiveram menor CCS em relação às amostras conservadas com bronopol (Tabela 2), independentemente da idade, como observado em outros estudos (Gonzalo et al., 2003; Seskena \& Jankevica, 2007).

Redução dos teores de gordura (Tabela 3) e lactose (Tabela 4) foi observada nas amostras refrigeradas conservadas com azidiol a partir do quinto dia de coleta em relação àquelas com bronopol refrigeradas.

O mesmo não ocorreu com os teores de proteína (Tabela 5) e sólidos totais (Tabela 6), cujos teores foram semelhantes entre amostras conservadas com azidiol e bronopol e mantidas sob refrigeração.

Os teores de gordura, proteína, lactose e sólidos totais e a CCS foram semelhantes, até sete dias após a coleta, quando as amostras foram conservadas com bronopol, independentemente da temperatura de armazenamento. Meyer (2003), utilizando temperaturas de armazenamento similares, observou resultados semelhantes. Amostras destinadas a análises de composição e CCS conservadas com bronopol e mantidas sob refrigeração podem ser analisadas em até sete dias, assim como amostras destinadas a análise de contagem bacteriana total conservadas com azidiol e refrigeradas.

No entanto, as reduções na CCS e nos teores de gordura e lactose inviabilizam a utilização de uma única amostra conservada com azidiol e refrigerada para a realização de todas as análises exigidas pela IN-51.

Tabela 2 - Logaritmo natural da CCS em amostras de leite conservadas com bronopol ou azidiol e analisadas em quatro idades

\begin{tabular}{|c|c|c|c|}
\hline \multirow[t]{2}{*}{ Temperatura $\left({ }^{\circ} \mathrm{C}\right)$} & \multicolumn{3}{|c|}{ Conservante } \\
\hline & Sem & Azidiol & Bronopol \\
\hline & & Amostra de 1 dia & \\
\hline 7 & $6,67 \pm, 009 \mathrm{bB}$ & $6,54 \pm, 008 \mathrm{aC}$ & $6,84 \pm, 006 \mathrm{aA}$ \\
\hline \multirow[t]{2}{*}{24} & & $6,43 \pm, 010 \mathrm{bB}$ & $6,83 \pm, 006 \mathrm{aA}$ \\
\hline & & Amostra de 3 dias & \\
\hline \multirow[t]{2}{*}{24} & & $6,14 \pm, 009 \mathrm{bB}$ & $6,76 \pm, 004 \mathrm{bA}$ \\
\hline & & Amostra de 5 dias & \\
\hline 0 & $6,64 \pm, 035 \mathrm{aA}$ & $6,57 \pm, 010 \mathrm{aA}$ & $6,72 \pm, 005 \mathrm{aA}$ \\
\hline 7 & $6,61 \pm, 027 \mathrm{aB}$ & $6,48 \pm, 006 \mathrm{aB}$ & $6,75 \pm, 009 \mathrm{aA}$ \\
\hline \multirow[t]{2}{*}{24} & & $5,81 \pm, 008 \mathrm{bB}$ & $6,50 \pm, 010 \mathrm{bA}$ \\
\hline & & Amostra de 7 dias & \\
\hline
\end{tabular}

Médias seguidas por letras maiúsculas diferentes nas linhas diferem $(\mathrm{p} \leq 0,05)$ pelo teste Tukey.

Médias seguidas por letras minúsculas diferentes nas colunas diferem $(\mathrm{p} \leq 0,05)$ pelo teste Tukey, dentro da idade. 
Tabela 3 - Porcentagem (\%) de gordura em amostras de leite conservadas com azidiol ou bronopol e analisadas em quatro idades

\begin{tabular}{|c|c|c|c|}
\hline \multirow{2}{*}{$\begin{array}{l}\text { Temperatura } \\
\text { de armazenamento }\left({ }^{\circ} \mathrm{C}\right)\end{array}$} & \multicolumn{3}{|c|}{ Conservante } \\
\hline & Sem & Azidiol & Bronopol \\
\hline & & Amostra de 1 dia & \\
\hline 0 & $3,63 \pm, 004 \mathrm{aA}$ & $3,60 \pm, 008 \mathrm{aB}$ & $3,61 \pm, 006 \mathrm{aAB}$ \\
\hline \multirow[t]{2}{*}{24} & & $3,60 \pm, 005 \mathrm{aA}$ & $3,61 \pm, 002 \mathrm{aA}$ \\
\hline & & Amostra de 3 dias & \\
\hline 0 & $3,63 \pm, 002 \mathrm{aA}$ & $3,60 \pm, 005 \mathrm{aB}$ & $3,61 \pm, 003 \mathrm{aAB}$ \\
\hline 24 & & Amostra de 5 dias & \\
\hline 0 & $3,65 \pm, 004 \mathrm{aA}$ & $3,62 \pm, 005 \mathrm{aB}$ & $3,62 \pm, 004 \mathrm{aB}$ \\
\hline 7 & $3,63 \pm, 003 \mathrm{aA}$ & $3,61 \pm, 003 \mathrm{aB}$ & $3,63 \pm, 001 \mathrm{aA}$ \\
\hline \multirow[t]{2}{*}{24} & & $3,61 \pm, 008 \mathrm{aA}$ & $3,62 \pm, 003 \mathrm{aA}$ \\
\hline & & Amostra de 7 dias & \\
\hline 0 & $3,65 \pm, 002 \mathrm{aA}$ & $3,63 \pm, 002 \mathrm{aA}$ & $3,63 \pm, 003 \mathrm{abA}$ \\
\hline
\end{tabular}

Médias seguidas por letras maiúsculas diferentes nas linhas diferem $(\mathrm{p} \leq 0,05)$ pelo teste Tukey.

Médias seguidas por letras minúsculas diferentes nas colunas diferem $(\mathrm{p} \leq 0,05)$ pelo teste Tukey dentro da idade.

Tabela 4 - Porcentagens (\%) de lactose em amostras de leite conservadas com azidiol ou bronopol e analisadas em quatro idades

\begin{tabular}{|c|c|c|c|}
\hline \multirow{2}{*}{$\begin{array}{l}\text { Temperatura } \\
\text { de armazenamento }\left({ }^{\circ} \mathrm{C}\right)\end{array}$} & \multicolumn{3}{|c|}{ Conservante } \\
\hline & Sem & Azidiol & Bronopol \\
\hline & & Amostra de 1 dia & \\
\hline 0 & $4,17 \pm, 018 \mathrm{bB}$ & $4,18 \pm, 009 \mathrm{bB}$ & $4,22 \pm, 003 \mathrm{aA}$ \\
\hline \multirow[t]{2}{*}{24} & & $4,21 \pm, 002 \mathrm{aB}$ & $4,23 \pm, 001 \mathrm{aA}$ \\
\hline & & Amostra de 3 dias & \\
\hline 0 & $4,21 \pm, 002 \mathrm{aAB}$ & $4,20 \pm, 001 \mathrm{aB}$ & $4,23 \pm, 002 \mathrm{aA}$ \\
\hline 24 & & Amostra de 5 dias & \\
\hline 0 & $4,19 \pm, 003 \mathrm{aB}$ & $4,17 \pm, 002 b B$ & $4,22 \pm, 004 \mathrm{aA}$ \\
\hline 7 & $4,18 \pm, 003 \mathrm{aB}$ & $4,20 \pm, 002 \mathrm{aB}$ & $4,23 \pm, 001 \mathrm{aA}$ \\
\hline \multirow[t]{2}{*}{24} & & $4,21 \pm, 002 \mathrm{aB}$ & $4,23 \pm, 001 \mathrm{aA}$ \\
\hline & & Amostra de 7 dias & \\
\hline 0 & $4,19 \pm, 002 \mathrm{aAB}$ & $4,17 \pm, 001 \mathrm{aB}$ & $4,20 \pm, 002 \mathrm{aA}$ \\
\hline
\end{tabular}

Médias seguidas por letras maiúsculas diferentes nas linhas diferem $(\mathrm{p} \leq 0,05)$ pelo teste Tukey.

Médias seguidas por letras minúsculas diferentes nas colunas diferem $(p \leq 0,05)$ pelo teste Tukey dentro da idade.

Tabela 5 - Porcentagem (\%) de proteína em amostras de leite conservadas com azidiol ou bronopol e analisadas em quatro idades

\begin{tabular}{cccc}
\hline Temperatura & & Conservante & \\
\cline { 2 - 4 } de armazenamento $\left({ }^{\circ} \mathrm{C}\right)$ & Sem & Azidiol & Bronopol \\
\hline & & Amostra de 1 dia & $2,98 \pm, 002 \mathrm{aA}$ \\
7 & $2,98 \pm, 012 \mathrm{aA}$ & $2,99 \pm, 005 \mathrm{aA}$ & $2,98 \pm, 001 \mathrm{aA}$ \\
24 & $2,97 \pm, 002 \mathrm{aA}$ & $2,98 \pm, 002 \mathrm{aA}$ & $2,98 \pm, 001 \mathrm{aA}$ \\
& & $2,98 \pm, 001 \mathrm{aA}$ & $3,01 \pm, 002 \mathrm{aA}$ \\
0 & $3,01 \pm, 002 \mathrm{aA}$ & Amostra de 3 dias & $3,02 \pm, 002 \mathrm{aA}$ \\
7 & $3,01 \pm, 000 \mathrm{aA}$ & $3,02 \pm, 002 \mathrm{aA}$ & $3,02 \pm, 002 \mathrm{aA}$ \\
& & $3,02 \pm, 002 \mathrm{aA}$ & $3,03 \pm, 004 \mathrm{aA}$ \\
7 & & $3,02 \pm, 003 \mathrm{aA}$ & $3,02 \pm, 001 \mathrm{aA}$ \\
24 & $3,03 \pm, 001 \mathrm{aA}$ & Amostra de 5 dias & $3,02 \pm, 002 \mathrm{aA}$ \\
7 & $3,04 \pm, 003 \mathrm{aA}$ & $3,04 \pm, 002 \mathrm{aA}$ & $3,02 \pm, 003 \mathrm{bA}$ \\
24 & & $3,04 \pm, 002 \mathrm{abA}$ & $3,03 \pm, 002 \mathrm{bA}$ \\
& & Amostra de 7 dias & $3,04 \pm, 002 \mathrm{abB}$ \\
\hline
\end{tabular}

Médias seguidas por letras maiúsculas diferentes nas linhas diferem $(\mathrm{p} \leq 0,05)$ pelo teste Tukey.

Médias seguidas por letras minúsculas diferentes nas colunas diferem $(\mathrm{p} \leq 0,05)$ pelo teste Tukey dentro da idade. 
Tabela 6 - Porcentagem (\%) de sólidos totais em cada conservante, temperatura e idade das amostras de leite

\begin{tabular}{|c|c|c|c|}
\hline \multirow[t]{2}{*}{ Temperatura $\left({ }^{\circ} \mathrm{C}\right)$} & \multicolumn{3}{|c|}{ Conservante } \\
\hline & Sem & Azidiol & Bronopol \\
\hline & & Amostra de 1 dia & \\
\hline 0 & $11,65 \pm, 062 \mathrm{bB}$ & $11,66 \pm, 025 \mathrm{aAB}$ & $11,73 \pm, 004 \mathrm{aA}$ \\
\hline 7 & $11,73 \pm, 003 \mathrm{aA}$ & $11,69 \pm, 002 \mathrm{aA}$ & $11,74 \pm, 002 \mathrm{aA}$ \\
\hline \multirow[t]{2}{*}{24} & & $11,70 \pm, 006 \mathrm{aA}$ & $11,74 \pm, 002 \mathrm{aA}$ \\
\hline & & Amostra de 3 dias & \\
\hline 0 & $11,76 \pm, 004 \mathrm{aA}$ & $11,72 \pm, 006 \mathrm{aA}$ & $11,77 \pm, 005 \mathrm{aA}$ \\
\hline 7 & $11,77 \pm, 002 \mathrm{aA}$ & $11,73 \pm, 002 \mathrm{aA}$ & $11,79 \pm, 003 \mathrm{aA}$ \\
\hline \multirow[t]{2}{*}{24} & & $11,75 \pm, 004 \mathrm{aA}$ & $11,79 \pm, 003 \mathrm{aA}$ \\
\hline & & Amostra de 5 dias & \\
\hline 0 & $11,76 \pm, 004 \mathrm{aA}$ & $11,72 \pm, 004 \mathrm{aA}$ & $11,78 \pm, 008 \mathrm{aA}$ \\
\hline 7 & $11,74 \pm, 004 \mathrm{aA}$ & $11,74 \pm, 003 \mathrm{aA}$ & $11,80 \pm, 002 \mathrm{aA}$ \\
\hline \multirow[t]{2}{*}{24} & & $11,75 \pm, 008 \mathrm{aA}$ & $11,79 \pm, 004 \mathrm{aA}$ \\
\hline & & Amostra de 7 dias & \\
\hline 0 & $11,76 \pm, 003 a A$ & $11,73 \pm, 003 a \mathrm{~A}$ & $11,75 \pm, 006 \mathrm{a} A$ \\
\hline 7 & $11,70 \pm, 008 \mathrm{aB}$ & $11,74 \pm, 003 \mathrm{aAB}$ & $11,80 \pm, 003 \mathrm{a} A$ \\
\hline 24 & & $11,75 \pm, 003 a \mathrm{~A}$ & $11,78 \pm, 010 \mathrm{aA}$ \\
\hline
\end{tabular}

Médias seguidas por letras maiúsculas diferentes nas linhas diferem (p£0,05) pelo teste Tukey.

Médias seguidas por letras minúsculas diferentes nas colunas diferem $(\mathrm{p} £ 0,05)$ pelo teste Tukey, dentro da idade.

\section{Conclusões}

Para atender às exigências previstas na IN-51, é necessária a coleta de duas amostras de cada fazenda, uma que deve ser conservada com bronopol, para determinação de contagem de células somáticas (CCS) e análise da composição e outra conservada com azidiol para contagem bacteriana total. A amostra para contagem bacteriana total pode ser analisada até sete dias após a coleta, desde que conservada com azidiol e mantida sob refrigeração a $7{ }^{\circ} \mathrm{C}$, sem aquecimento ou congelamento.

\section{Referências}

BARCINA, Y.; ROS, G.; RINCON, F. Azidiol as a preservative for milk samples. In: ANALES DE VETERINARIA DE MURCIA, 1987, Murcia. Anales... Murcia: Universidad de Murcia, 1987. p.65-69.

BENTLEY INSTRUMENTS. Bentley 2000: operator's manual. Chaska, 1995a. p.77.

BENTLEY INSTRUMENTS. Somacount 300: operator's manual. Chaska, 1995b. p.12.

BENTLEY INSTRUMENTS. Bactocount 150: operator's manual. Chaska, 2004. p.35.

BERTRAND, J.A. Influence of shipping container, preservative and breed on analysis of milk components of shipped samples. Journal of Dairy Science, v.79, n.1, p.145-148, 1996.

BRASIL. Instrução Normativa nº. 51, de 20 de setembro de 2002. Aprova os regulamentos técnicos de produção, identidade, qualidade, coleta e transporte de leite. Diário Oficial da União, Brasília, Seção 1, p.13, 21 set. de 2002.

ELIZONDO, J.A.; EZCURRA, P.; SAIGOS, E. et al. Efficiency of the proportion of azidiol on preservation in ewe's milk samples for analysis. Food Control, v.18, p.185-190, 2007.

ESTADOS UNIDOS. Food and Drug Administration. Grade “A” pasteurized milk ordinance. Washington, 2001. p.57.

GONZALO, C.; MARTINEZ, J.R.; CARRLEDO, J.A. Fossomatic cell-counting on ewe milk: comparison with direct microscopy and study of variation factors. Journal of Dairy Science, v.86, n.1, p.138-145, 2003.

INTERNATIONAL DAIRY FEDERATION. Milk and milk products: methods of sampling. Brussels, 1995. p.25. (IDF Standard, $50 \mathrm{C}$ ).

INTERNATIONAL DAIRY FEDERATION. Milk and milk products: guidance on sampling. Brussels, 2005. p.19. (IDF Standard, 50 - ISO/DIS 707).

MEYER, P.M. Fatores não nutricionais que afetam as concentrações de nitrogênio uréico no leite. 2003. 131f. Tese (Doutorado em Ciência Animal e Pastagens) - Escola Superior de Agricultura “Luiz de Queiroz”, Universidade de São Paulo, Piracicaba.

MONARDES, H.G.; MOORE, R.K.; CORRIGAN, B. et al. Preservation and storage mechanisms for raw milk samples for use in milk-recording schemes. Journal of Food Protection, v.59, n.2, p.151-154, 1996.

NINANE, V.; REU, K.; OGER, R. et al. Évaluation du Bactoscan FC pour la numeration des bactéries du lait cru. Le Lait, v.80, p.527-538, 2000.

SESKENA, R.; JANKEVICA, L. Influence of chemical preservatives on the quality and composition indices of raw milk. Acta Universitatis Latviensis, v.723, p.171-180, 2007.

STATISTICAL ANALYSIS SYSTEM - SAS. SAS user's guide: version 9.1. Cary: SAS Institute, 2006. 235p.

VAN DE VOORT, F.R.; KERMASHA, S.; SMITH, J.P. et al. A study of the stability of record of performance milk samples for infrared analysis. Journal of Dairy Science, v.70, p.1515-1523, 1987. 